\title{
The SOS Pesca Project: A Multinational and Intersectoral Collaboration for Sustainable Fisheries, Marine Conservation and Improved Quality of Life in Coastal Communities
}

\author{
Valerie Miller MS, Ania Mirabal-Patterson MS, Elisa García-Rodríguez PhD, Kendra Karr PhD, Daniel Whittle JD, \\ National Center for Protected Areas Working Group (CU)*
}

\begin{abstract}
Healthy fisheries, particularly small-scale fisheries, are closely linked to prosperous and healthy coastal communities and resilient marine environments. Cuba's marine and coastal ecosystems are highly biodiverse and support fisheries vital to food security and the national economy. Cuban government and state institutions, scientists, managers and fishers-along with colleagues from other countries-have expressed growing concern about the decline of fishing resources. In 2012, under the aegis of the National Center for Protected Areas, Cuban institutions from the Ministry of Science, Technology and Environment and the Ministry of Foreign Investment partnered with the Italian nongovernmental organization, COSPE Onlus, to launch SOS Pesca, a four-year project to achieve sustainable fisheries management, conserve marine habitats and improve quality of life in two Cuban fishing communities (Guayabal in Las Tunas Province and Playa Florida in Camagüey Province). SOS Pesca involved the municipal governments of Amancio Rodríguez (in Las Tunas Province) and Florida (in Camagüey Province), delegates to the Municipal Assembly of People's Power (municipal government) from Guayabal (Amancio Rodríguez Municipality) and Playa Florida (Florida Municipality), the state-owned fishing industry, private fishers, local families, protected area officials and staff scientists, municipal governments and international nongovernmental organizations. By the end of 2012, a new US-Cuban collaboration emerged when COSPE recruited Environmental Defense Fund to
\end{abstract}

provide scientific and technical support, trainings and exchanges focused on fisheries. SOS Pesca succeeded at community, regional fishing zone and national levels. Outcomes included: an assessment of finfish identifying species most vulnerable to fishing (methods and capacities), a proposed management plan for finfish, a National Plan of Action for sharks and rays, two marine protected areas established, increased employment through socioeconomic alternatives, revitalization of community environmental brigades, and greater capacity to use fishery assessment methods and develop management strategies. Perhaps the greatest achievement was communities' and fishers' changed perceptions of their marine environment, the need for conservation and sustainable resource management, and their active role in this objective. SOS Pesca spurred a more participatory form of integrated marine and coastal management in Cuba-one that integrates fisheries and spatial management, links fishing families and coastal communities with scientists and administrators to find solutions that support sustainability, and connects economic alternatives to communitybased conservation and improved food security. This innovative multinational collaboration benefited coastal communities, marine and coastal ecosystems and international cooperation.

KEYWORDS Small-scale fisheries, fisheries management, food security, marine protected areas, community-based management, institutions, marine conservation, local government, Cuba, USA

\section{INTRODUCTION}

Fisheries, particularly small-scale fisheries, are closely linked to healthy marine environments and healthy and prosperous coastal communities.[1] Small-scale fisheries provide important nutrition and support food security, poverty reduction and economic development at local and national levels.[1] Globally, small-scale fisheries contribute to half of total fish catches and employ an estimated $90 \%$ of the world's 37 million fishers, while 3 billion people depend on fish as an important source of protein.[2-4] Small-scale fisheries, many of which lack governance and a data collection system to guide management,[5] are more likely to be threatened by overfishing and are typically less well-managed than large-scale fisheries.[6]

Cuba's marine and coastal ecosystems are highly biodiverse and support various fishing activities around the entire island. The country's marine fisheries are vital to the economy, particularly

IMPORTANCE SOS Pesca created an innovative multinational, multisectoral collaboration for sustainable fisheries in Cuba based on scientific evidence, participation and local government support, for the benefit of communities, ecosystems and international cooperation. because of exports like lobster and shrimp, and because they provide critical employment, income and food to coastal communities and residents across the island. Cuba's fishing sector includes the state-owned industry that operates 35 ports and employs nearly 14,000 people, and the private sector that operates from 196 fishing bases and involves 18,638 private commercial fishers and 17,657 noncommercial private fishers. Sport-recreational fisheries and research fisheries are also vital.[7]

Cuba's long history of scientific research and environmental policies has enabled protection and conservation of biodiversity and sustainable resource use. The government has a nationwide system of protected areas that currently covers approximately $17.2 \%$ of the country's land and $25 \%$ of its insular platform (i.e., coastal waters).[8]

Although Cuba's science, conservation and resource management programs are some of the best in the Caribbean, the complex nature of their fisheries, which catch species with varying levels of vulnerability to fishing, makes it challenging to evaluate their status and implement recovery measures for overfished populations. [9] Cuban fisheries statistics recorded over the last 60 years have allowed researchers to conduct extensive analysis of catches. [10-13] In the most recent, Baisre examined catch trends over 80 years and estimated that up to $74 \%$ of commercial fish species are overexploited and 5\% collapsed; he notes that analyses based on 
catch data alone allow for an initial estimate and can be compared with other methods to develop a more reliable indicator of fisheries status.[13]

To better understand the status of fisheries in Cuba, a working group of industry, science and management institutions is assessing the potential benefits of recovering depleted fish stocks using a bioeconomic method developed by Costello,[14] with technical support from Environmental Defense Fund (EDF), USA. As this scientific work continues in Cuba, managers and fishers report declining stocks, similar to trends seen globally.[9,13,15]

Due to the socioecological nature of fisheries health and management problems, linked to overall marine ecosystem health and coastal communities' livelihoods, a multidisciplinary and international collaboration is required to address diverse needs and challenges and to apply best practices.

\section{COШABORATION}

Antecedents In 2012, the National Center for Protected Areas (CNAP) of the Ministry of Science, Technology and Environment (CITMA) and the Ministry of the Food Industry (MINAL) teamed up with the Italian NGO, COSPE Onlus and the office of World Wildlife Fund-Netherlands (WWF-NL) in Cuba to develop SOS Pesca, a four-year project designed to achieve fisheries sustainability, conserve marine habitats and improve the quality of life in two fishing communities in southern Cuba.[15] SOS Pesca targeted Playa Florida and Guayabal, located in the southeastern region of the country (Fishing Zone A), which provides $40 \%$ of Cuba's finfish fisheries and which surrounds Cuba's largest marine protected area (MPA), Jardines de la Reina National Park (Figure 1).

Figure 1: Map of Cuba highlighting SOS Pesca implementation area
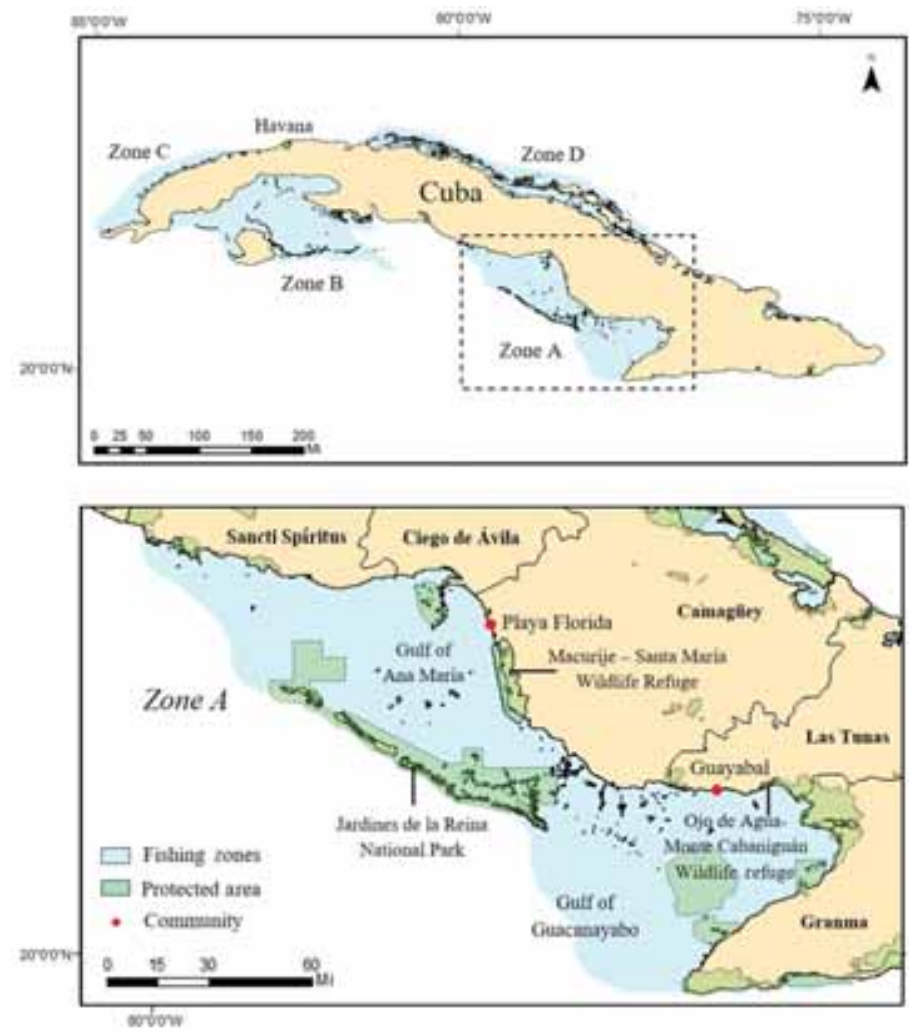

The successful results of other projects carried out along the north and south coasts of Cuba (such as Protection of Biodiversity and Sustainable Development in the Sabana-Camagüey Ecosystem, and Application of a Regional Approach to Management of Marine and Coastal Protected Areas in Cuba's Southern Archipelagos) proved to be alternatives for sustainable fishing and marine conservation. These projects were developed with the support of the Global Environmental Facility. SOS Pesca consolidated the strategy as a way to integrate sustainable fisheries management with these broader marine conservation efforts.

At the start of the project, stakeholders identified problems at various levels that SOS Pesca would address, either directly or indirectly, and helped design activities that were carried out from 2012-2016. Stakeholders included members of the two communities, municipal governments, fishing industry representatives, national and provincial management agencies and international NGOs.

Objectives SOS Pesca's main objectives were to strengthen two established marine and coastal protected areas (functioning within a Management Plan); stop the decline of fish populations; create sustainable livelihood alternatives, with emphasis on opportunities for women; develop a strong community-based and enterprisebased fisheries management program; improve income and quality of life in communities; and organize exchanges across Cuba and the Caribbean. While the focus was on two communities (Playa Florida and Guayabal), activities would engage a broader constituency across southern Cuba and within provincial and national level institutions.

Justification At the community level, problems in Playa Florida and Guayabal included: few employment alternatives, marine habitat degradation, illegal harvest of marine resources, poor knowledge of environmental and fisheries regulations, gender inequity, few options for fresh produce, rising sea levels and damage from severe weather events linked to climate change. In Fishing Zone A, the identified problems were: illegal fishing in MPAs, limited data on multispecies fishery (60+ species of fish), no catch quotas for fish, lack of communication between communities, limited opportunities for communities to work together and little community support for the protection of the two MPAs identified. At the national level, stakeholders diagnosed problems that jeopardize sustainability: lack of data on multispecies fisheries, no catch quotas and limited management of finfish, insufficient involvement of community stakeholders in fisheries management and limited interinstitutional coordination. Improving finfish management and recovering stocks was of concern at all levels due to the high volume and value of the catch of many species and, in some cases, vulnerability of spawning aggregations to overfishing.[9,12,15,16]

Participating institutions and contributions The European Union (EU) provided $80 \%$ of SOS Pesca project funds, with additional support from US-based philanthropies through EDF. EDF, with COSPE Onlus, raised the additional 20\% in matching funds (required by the EU) from the MacArthur Foundation (USA) and provided in-kind scientific, technical and administrative support for fisheries-focused activities. CNAP was the national coordinator of the project in Cuba, assuming the role of coordinator at provincial, municipal and local levels and providing expertise in environmental education, geographic 
information systems, biological monitoring and protected areas management. COSPE Onlus, the foreign counterpart, was the primary international coordinator and facilitated stakeholder coordination, fiscal management, and expertise related to community participation and gender equity. WWF-NL's office in Cuba played a key role in drafting the project, contributing to outreach activities and training, and connecting different partners.

MINAL's Fisheries Regulations and Sciences Directorate was responsible for coordinating various capacity-building activities, linking scientific expertise to fisheries management. The Center for Fisheries Research provided scientific oversight for data collection and assessment of fishery resources.

Protected-area staff and specialists from the National Enterprise for the Protection of Flora and Fauna (ENPFF) participated in project planning and organization, carried out field expeditions and trained the neighboring communities of Guayabal and Playa Florida.

COSPE Onlus and WWF-NL recruited EDF to provide scientific and technical support related to fisheries science, evaluation and management, aligned with SOS Pesca objectives. EDF's Oceans program works around the world to help design science-based fisheries management and habitat conservation strategies that rebuild fish populations and improve livelihoods of fishers and other stakeholders. Since 2000, EDF has collaborated with Cuban institutions on initiatives to conserve Cuba's biodiversity and protect shared marine ecosystems in the Gulf of Mexico and the wider Caribbean Sea. For example, Cuba is home to spawning grounds for commercially important snappers that produce larvae that make their way to some other neighboring countries.[16] Migratory sharks like the longfin mako have been found to travel from Cuban to US waters.[17] EDF supports Cuban projects like SOS Pesca that bring together diverse fisheries stakeholders to learn from each other and exchange best practices because both Cuba and the USA benefit from international collaboration on resource management and conservation.

Other Cuban institutions, such as ENPFF, CITMA delegations from Las Tunas and Camagüey Provinces, the Center for Local and Community Development (CEDEL) and the Food Industry Enterprise Group (GEIA, which directs Cuba's fishing production), participated actively in project activities based on their missions: environmental education, monitoring, management and conservation of protected areas (ENPFF, CITMA); community development (CEDEL) and fishing operations (GEIA). MINAL's National State Inspection Office ensured compliance with current fisheries management regulations through their enforcement systems. Colombia's José Benito Vives de Andreis Institute of Marine and Coastal Research provided scientific contributions related to the Caribbean Region and coordinated exchanges between Colombia and Cuba.

CITMA, CNAP, COSPE Onlus and WWF-NL began participatory planning in 2010 and recruited the other partners. They identified Playa Florida and Guayabal as the pilot communities due to their dependence on fishing and their vulnerability to impacts of climate change (sea level rise and more severe storms in particular). Together, stakeholders identified goals, activities and indicators, and developed project documents. By 2012, the project was formally approved by Cuba's Ministry of Trade and
Foreign Investment, which guides and regulates the processes of collaboration in the country, including the signing of terms of reference in accordance to national laws.

\section{ACTIVTTES}

The project's main activities in 2012-2016 included:

1. MPA Capacity building and training

- Implementing participatory processes to establish and strengthen two MPAs and an integrated coastal management zone

- Strengthening two MPAs through management and monitoring plans, and constructing and supplying biological stations

- Developing and implementing monitoring plans by carrying out expeditions to diagnosis and map marine and coastal ecosystems, collecting baseline biological, ecological and geographic information

- Strengthening enforcement of MPAs and fishing regulations through trainings for officers and decision-makers, supplying equipment and community workshops on comanagement strategies

- Providing training on MPA management, enforcement and compliance, monitoring and geographic information systems

\section{Promoting fishery sustainability}

- Carrying out training programs on stock assessments and fisheries management, through workshops and international trainings

- Implementing a needs-based training program for fishers on sustainable fisheries management and governance and on-the-water safety, and developing educational materials

- Identifying and adopting best practices for sustainable fishing through national and international fisher exchanges and "friendlier" fishing gear

- Installing new positioning systems technology and repairing state and private fishing boats to improve work safety

- Assessing fishery resources and developing a pilot fisheries management plan for Zone A through participatory workshops and scientific expeditions

\section{Promoting sustainable livelihoods and supporting} local communities

- Stimulating community-led initiatives to strengthen community identity, environmental awareness and outreach, by providing support and supplying materials to local institutions for educational, cultural and recreational activities

- Identifying and implementing economic alternatives in two communities by assessing local capacities and needs, conducting learning exchanges with fishing communities in Cuba and abroad, and supplying materials and technical expertise to develop projects

- Implementing an educational campaign and training, bringing together community stakeholders (themes include environmental sustainability, gender relations, project management)

- Producing educational materials to communicate to national and international audiences

\section{Promoting networking between fishers and fishing} communities

- Exchanges between Cuban fishing communities

- Exchanges of fishers and fishery managers with other Caribbean countries and the USA

- Carrying out national and international workshops bringing 


\section{Lessons in International Cooperation}

together fishers, fishery managers, scientists and conservation practitioners

- Participating in international conferences, sharing experiences with broader scientific and technical audiences

During initial planning, project organizers identified qualitative and quantitative indicators of success for each activity and made adaptations during implementation. Due to the project's interdisciplinary nature, all activities involved stakeholders from the various partnering institutions. Project coordinators took advantage of any scheduled activity in the communities to accomplish as much as possible, conducting training workshops, delivering supplies and planning next steps. Project coordinators at the national level and coordinators at the project sites maintained constant communication, a major factor in the success of the participatory process to plan, execute and evaluate all activities.

In total, these activities directly involved and benefited 2000 community members from Playa Florida and Guayabal, 10 local government representatives, more than 200 stakeholders from national institutions and more than 50 individuals from international organizations. Through international exchanges and conferences, SOS Pesca engaged hundreds of others doing similar work around the world.

\section{ACHIEVEMENTS}

Cuba has a long and strong tradition of managing fisheries and conserving natural areas. As a result of SOS Pesca, marine and coastal management is being strengthened in Cuba by integrating fisheries and spatial management among all relevant national and local institutions, educating provincial, municipal and local governments, providing more opportunities for fishing families and coastal communities to collaborate directly with scientists and managers towards solutions that support sustainability of fisheries and natural resources, and facilitating economic alternatives to community-based conservation and improved food security. The collaboration achieved results at community, regional fishing zone and national levels (Table 1).

\section{ANALYSIS \\ The collaboration between US and Cuban stakeholders centered on certain project results. For example, Cuban and US specialists worked together to apply new tools to assess the vulnerability of fish populations to fishing in each of the four fishing zones (productivity and susceptibility analysis) and to establish new management measures.[9] Through jointly led workshops and exchanges, more than 50 Cuban marine scientists, managers, fishing sector representatives and other partners are now able to use methodologies to evaluate and manage fish stocks when data from the field is limited. EDF introduced adaptive fisheries assessment, management and governance tools, and the Framework for Integrated Stock and Habitat Evaluation, for these and future efforts in Cuba.}

International exchanges played a key role in sharing stories of success, failure and lessons learned among fishers, managers and scientists. SOS Pesca stakeholders participated in exchanges with EDF and fishing communities in the USA (Morro Bay, CA; Cape Cod, MA) and the Mexican states of Yucatan and Quintana Roo. They shared their experiences and learned firsthand how fishers and fishing organizations have worked with governments to develop and implement fisheries recovery and habitat conservation programs that benefit coastal communities and enhance pride around sustainable fishing livelihoods. The collaboration extended from local to international through these experiences that have left their mark on science and local knowledge, especially across the wider Caribbean and Gulf of Mexico. Another strong US-Cuban collaboration undertaken through the project was the process led by the Cuban government to develop, adopt and implement a National Plan of Action for Conservation and Management of Sharks and Rays (NPOA-Sharks). UN FAO defines NPOAs and encourages all member states to develop and implement an NPOA-Sharks. Cuba's NPOA-Sharks lays out the information needed to take management action and set regulatory measures over the long term and creates a roadmap for healthier shark populations and sustainable fisheries in the future.[7]

Lessons learned from SoS Pesca serve as a reference for other localities and regions of Cuba. At the regional scale of Fishing Zone A in southeastern Cuba, the project also produced major achievements. The findings of the national vulnerability analysis highlighted regional differences in finfish fisheries and demonstrated the need to seek specific management for all four fishing zones.[9]

At the end of the project, MINAL proposed an unprecedented finfish management plan for Zone A that incorporates perspectives from fishers and collaborators, and includes potential administrative and fisheries management measures. Project collaborators also worked together to establish an integrated coastal management zone that encompasses the marine waters off Guayabal and the Ojo de Agua-Monte Cabaniguán MPA, integrating both spatial and fisheries management for marine conservation.

At the local level, SOS Pesca developed a shared vision of the importance of protected areas for healthy ecosystems, fisheries, and communities. Local governments and community stakeholders worked together with fishery and protected area specialists and researchers to collect data, create management plans and monitor MPAs. This effort culminated with the establishment of the Macurije-Santa María Wildlife Refuge and improved management of the Ojo de Agua-Monte Cabaniguán Wildlife Refuge. Both MPAs now have community support for their continued protection. The self-organization demonstrated in Playa Florida and Guayabal where members of the community revitalized their Community Marine Stewardship and Enforcement Brigades is also significant.

Local governments and residents of Playa Florida and Guayabal identified opportunities and developed economic alternatives that are compatible with sustainable fisheries and MPAs and improve local nutrition, income and well-being. With support from partners, the communities created oyster mariculture projects, including cultivation and processing, within their respective local MPAs, resulting in new jobs and greater income for fishers and for the women who process oysters. They organized a women's textile workshop, established greenhouses to supply local produce, and developed a pilot blue crab fishery to benefit from a resource that had not been harvested in some time. Oyster mariculture in particular became an alternative production strategy that allowed fishing industry ports to reduce pressure on other species, sustain and create jobs, and build greater support for MPAs, which safeguard the habitat conditions needed for oyster production. 
Table 1: Selected SOS Pesca outcomes ${ }^{\mathrm{a}}$ at community, regional and national levels

Goal
End overfishing practices and
rebuild fish stocks

N National fish vulnerability assessment completed, identifying fish stocks most vulnerable to overfishing and regional differences, leading to:

$R$ first proposed regional management plan for finfish in Zone $A$, and

$\mathrm{R}$ fishing communities' perception that important fish species such as lane snapper, grey mullet, sea bream, king mackerel and Atlantic croaker are seen more frequently.

$\mathrm{N}$ Fishers and managers share a vision for making fisheries sustainable, and fishers are asking to develop new management plans.

N National Plan of Action for Sharks and Rays, a binding policy framework, is established to protect sharks and rays.

$\mathrm{N}$ Monitoring protocols and data collection forms are established for commercially important species, and a regulations guidebook for marine resources is created.

C Selective fishing gear is accepted by communities (circular hooks, fish traps, nets with greater mesh size that allow smaller fish to escape, obligatory use of escape devices in shrimp capture)

C With implementation of new positioning devices, GPS and sonar, fishing behavior in Guayabal and Playa Florida shift to target higher-quality species and reduced catch of juvenile and nontarget fish by $7 \%$.

C Newly established MPA (Macurije-Santa María Wildlife Refuge) and improved management of another MPA (Ojo de Agua-Monte Cabaniguán Wildlife Refuge), both with community support, management plans, baseline data, zoning, maps and biological stations.

Protect critical marine and coastal habitats

$\mathrm{C}$ With recovery of mangroves, communities report that juvenile fish are seen in abundance and birds such as the flamingo and Zapata rail have returned.

C Community involvement in protected areas has contributed to an increased presence of the Cuban crocodile (C. acutus), a native species with international conservation interest.

C Fishers communicate their new respect for MPAs; comanagement valued and understood.

$\mathrm{R}$ Coordination between protected areas and local state-owned fishing bases and private commercial fishers exemplifies best practices shared across the region.

$\mathrm{R}$ Integrated coastal management zone incorporating fishing areas and protected areas established off the coast of Las Tunas Province with participation from communities and local and regional institutions

Develop a strong communitybased fisheries management program

$\mathrm{R}$ Technological improvements in the fishing sector (GPS and sonar) contribute to more effective and efficient catches that translate into cost savings and higher income.

C With strengthened leadership and local capacities, representatives from Playa Florida and Guayabal are sharing their experiences with other communities and willing to exchange lessons learned with the rest of Cuba.

C Both communities revitalized local Community Marine Stewardship and Enforcement Brigades.

C Community members report improved family dynamics and gender equity.

C Youth Environmental Clubs created in schools in Guayabal and Playa Florida.

C Community pride strengthened through over 40 community-led environmental, cultural and recreational activities.

Improve fishing communities' income and quality of life through outreach and sustainable economic alternatives

C Work safety improved for fishers through maintenance and repair on 76 boats.

C New economic alternatives in Guayabal and Playa Florida have diversified and created employment with new and greater income sources (212 jobs created or modified, 81 for women):

o new oyster farms in each community support jobs in production and processing

0 new greenhouse in Playa Florida increased local food production

o women's textile shop in Guayabal

o new pilot blue crab fishery (developed after its fishery potential was tested)

N Stakeholders share experiences with other fishing zones at national environmental conferences, with EDF and partners at learning exchanges in the US (San Francisco, Boston), Mexico (La Paz, Mexico City, Yucatan, Quintana Roo), Guatemala, Colombia and Dominican Republic.

Exchange experiences across Cuba and the Caribbean

N 10 best practices of fisheries sustainability and economic alternatives were identified in Cuba, Mexico, Colombia, the Dominican Republic, the USA, Belize, Chile, Italy and Spain, and were disseminated.

$\mathrm{N}$ An informal network of people and organizations is working together and exchanging best practices related to fisheries and marine conservation.

areported by project stakeholders in project documents and during final evaluation workshop, April 2016

blevel of impact: community (C), national (N), regional (R, Fishing Zone A in southeastern Cuba)

EDF: Environmental Defense Fund GPS: global positioning system MPA: marine protected area

Source: references $7,9,15,18$

Local governments, related institutions and residents of Playa Florida and Guayabal are now more aware of the need for environmental protection and more sustainable fishing and are helping to find solutions. During SOS Pesca, international and national exchanges highlighted comanagement where fishers support monitoring and resource management. According to community representatives, these experiences helped build environmental consciousness and the belief within these communities that they too could actively protect their resources and reap benefits in the future. Project collaborators and leaders in the fisheries sector recognized that the greatest achievement was the change in how communities and fishers see their marine environment, the need for conservation and the sustainable management of resources, and their active role in this mission.

The project officially ended in 2016, but the networks of scientists, managers, fishers and their families, coastal communities, NGOs and other stakeholders who came together across Cuba and exchanged experiences with their counterparts in the USA and other countries remain intact and are growing. Fishing managers, fishers and community representatives from Playa Florida and Guayabal have become ambassadors for sustainable fishing, 
marine conservation and alternative livelihoods across the island, sharing their experiences with other communities.

Since most of SOS Pesca was carried out before Cuba and the USA resumed diplomatic relations in 2015, EDF's contribution and activities (e.g., travel, financial support) were somewhat constrained by regulations and politics. Nonetheless, with the support of Cuban and international partners, the organization was able to contribute in a robust fashion. Multistakeholder project processes involving national and international actors bring diverse benefits but also confront various obstacles. These challenges can be addressed up front, however, through transparency and by creating processes that allow national and international institutions to coordinate on the necessary administrative, budgetary and reporting systems for project implementation.

The main lessons learned that can be applied to future international collaborations in Cuba or elsewhere from the sustainable fisheries perspective include: understanding that community dynamics are key for fishery reform and that families need to be involved, not just fishers; exchanges between fishing communities, scientists and managers are effective in identifying a common language and vision, building trust and enabling success; connecting and combining multiple themes during activities can result in broader participation, project identity and ownership; face-to-face communication among communities, scientists and policymakers allows a better dialogue, and can help generate national impact. Partners agree that the most important result was the communities' changed perception of the importance of sustainable fisheries and marine conservation and understood that this buy-in for fisheries reform was only possible because communities were offered the opportunity to develop alternatives.

\section{ACKNOWLEDGMENTS}

We thank Dr. Rafael Puga and José L. Gerhartz for reviewing the manuscript and Jorge Losoya for the map. We acknowledge all Cuban partner institutions for significant in-kind contributions, as well as COSPE Onlus and WWF-NL. We thank the John D. and Catherine T. MacArthur Foundation, the Ford Foundation, the Turner Foundation, the Christopher Reynolds Foundation and the Flora Family Foundation for support for EDF's work on the project.

Special thanks to the scientists and workers at CNAP, CEDEL, MINAL, ENPFF, Cuba's Forestry Service and Coast Guard for contributing to the Project, and particularly to participating communities in Guayabal (Las Tunas Province) and Playa Florida (Camagüey Province). - > $/$ -

\section{REFERENCES}

1. Food and Agriculture Organization. Voluntary Guidelines for Securing Sustainable Small-Scale Fisheries in the Context of Food Security and Poverty Eradication. Rome: Food and Agriculture Organization; 2015. 34 p.

2. Food and Agriculture Organization. State of the World's Fisheries and Aquaculture. Rome: Food and Agriculture Organization; 2014. 243 p.

3. Food and Agriculture Organization. FAO Yearbook. Fishery and Aquaculture Statistics. Rome: Food and Agriculture Organization; 2014. 105 p.

4. Basurto X, Virdin J, Smith H, Juskus R. Strengthening Governance of Small-Scale Fisheries: An Initial Assessment of the Theory and Practice. Portland (ME): Oak Foundation; 2017 Jul. 123 p.

5. Salas S, Chuenpagdee R, Seijo JC, Charles A. Challenges in the assessment and management of small-scale fisheries in Latin America and the Caribbean. Fisheries Res. 2007 Oct;87(1):5-16.

6. Costello C, Ovando D, Hilborn R, Gaines SD, Deschenes O, Lester SE. Status and solutions for the world's unassessed fisheries. Science. 2012 Oct;338(6106):517-20.

7. Ministry of the Food Industry (CU). National Plan of Action for the Conservation and Management of Chondrichthyes of the Republic of Cuba. Havana: Ministry of the Food Industry (CU); 2015. 48 p. Spanish.

8. National Center for Protected Areas (CU). Plan del Sistema Nacional de Areas Protegidas 20142020: Resumen Ejecutivo. Havana: Ministry of Science, Technology and the Environment (CU); 2013. 365 p. Spanish.

9. Puga R,Valle S, Kritzer J, Delgado G, de León ME, Giménez E, et al. Vulnerability of nearshore tropical finfish in Cuba: Implications for scientific and management planning. Bull Marine Sci. 2018;94(2)

10. Claro R, Baisre J, García-Arteaga JP. Evolución y manejo de los recursos pesqueros. In: Claro R, editor. Ecología de los Peces Marinos de Cuba. Havana: Cuban Academy of Sciences, Institute of Oceanology; 1994. p. 435-92. Spanish.

11. Claro R, Baisre J, Lindeman K, García-Arteaga J. Cuban fisheries: historical trends and current sta- tus. In: Claro R, Lindeman K, Parenti L, editors. Ecology of the Marine Fishes of Cuba. Washington, D.C.: Smithsonian Institution Scholary Press; 2002 Feb 17. p. 179-93.

12. Claro R, Sadovy de Mitcheson Y, Lindeman K García-Cagides A. Historical analysis of Cuban commercial fishing effort and the effects of management interventions on important reef fishes from 1960-2005. Fish Res. 2009;99:7-16.

13. Baisre JA. An overview of Cuban commercial marine fisheries: the last 80 years. Bull Marine Sci. 2017 Aug 9. Epub ahead of print.

14. Costello C, Ovando D, Clavelle T, Strauss CK, Hilborn R, Melnychuk MC, et al. Global fishery prospects under contrasting management regimes. Proc Natl Acad Sci USA. 2016 May 3;113(18):5125-9.

15. Proyecto SOS Pesca. SOS PESCA: Comunidades del sur oriente de Cuba al rescate de la pesca sostenible. Havana, Cuba: PALCOGRAF; 2017. ISBN: 9789592870734 . Spanish.

16. Kough AS, Claro R, Lindeman KC, Paris CB. Decadal analysis of larval connectivity from Cuban snapper (Lutjanidae) spawning aggregations based on biophysical modeling. Marine Ecol Progr Series. 2016 May 25;550:175-90.

17. Hueter RE, Tyminski JP, Morris JJ, Ruiz Abierno A, Angulo Valdés J. Horizontal and vertical movements of longfin makos (Isurus paucus) tracked with satellite-linked tags in the northwestern Atlantic Ocean. Fishery Bull. 2017:115(1):101-16.

18. COSPE Onlus (IT); National Center for Protected Areas (CU); Ministry of the Food Industry (CU). Informe Final del Proyecto SOS Pesca para la Unión Europea. Florence: COSPE; 2017. Spanish.

\section{THE AUTHORS}

Valerie Miller (Corresponding author: vmiller@ edf.org), specialist in environmental communication with a master's degree in human dimensions of natural resources. Senior Manager, Cuba Oceans Program, Environmental Defense Fund (EDF), Austin (TX), USA.
Ania Mirabal-Patterson, sociologist with a master's degree in local public administration. previously with COSPE Onlus, Florence, Italy.

Elisa García-Rodríguez, biologist specializing in use, management and preservation of natural resources, with a doctorate in biological sciences. Advisor to the Minister, Ministry of the Food Industry, Havana, Cuba.

Kendra Karr, marine biologist with a doctorate in ecology and evolutionary biology. Scientist, Oceans Program, EDF, San Francisco, USA.

Dan Whittle, attorney specializing in environmental and energy law. Senior director, Oceans Program, EDF, Raleigh (NC), USA.

*National Center for Protected Areas Working Group (members: Yunaika Álvarez Carrazana, Augusto de Jesús Martínez Zorrilla and Carlos Alberto Diaz Maza), Ministry of Science, Technology and Environment, Havana, Cuba.

Submitted: October 27, 2018

Approved for publication: April 9. 2017 Disclosures: None 